\title{
Electroconvulsive Therapy in the Eyes of Undergraduate Nursing Students
}

\author{
Monday N. Igwe ${ }^{*}$, Appolos C. Ndukuba², Chukwuma M. Attama3 ${ }^{3}$ Pleasure N. Ogbonna4, \\ Chinonyerem Igwe 1 \\ ${ }^{1}$ Department of Psychological Medicine, Federal Teaching Hospital, Abakaliki, Nigeria \\ ${ }^{2}$ Department of Psychological Medicine, University of Nigeria Teaching Hospital, Ituku-Ozalla, \\ Nigeria \\ ${ }^{3}$ Federal Medical Centre, Umuahia, Nigeria \\ ${ }^{4}$ Federal Neuropsychiatric Hospital, Enugu, Nigeria \\ Email: "mondayigwe@yahoo.com, appolosndu@yahoo.com, katad2002@yahoo.com, surelyogb@yahoo.com, \\ nonyeremigwe@yahoo.com
}

Received 12 September 2014; revised 10 October 2014; accepted 4 November 2014

Academic Editor: Rie Chiba, Jichi Medical University, Japan

Copyright (C) 2014 by authors and Scientific Research Publishing Inc.

This work is licensed under the Creative Commons Attribution International License (CC BY).

http://creativecommons.org/licenses/by/4.0/

(c) (i) Open Access

\section{Abstract}

Despite the fact that electroconvulsive therapy (ECT) is an established safe and effective procedure, its use has continued to attract controversy with considerable stigma associated with it. This often overshadows the established effectiveness. Poor knowledge, negative attitude and bias towards ECT by the nurses may translate to poor education and support to patients from whom they are expected to obtain informed consent before an ECT procedure. This study assessed the perception of undergraduate nursing students of a Nigerian university about ECT. A total of 81 students who had completed all relevant lectures and practical/clinical exposures in psychiatry as prescribed in their academic curricular participated in the study. All the consenting students were administered the socio-demographic questionnaire and modified questionnaire on attitude and knowledge of electroconvulsive therapy (QuAKE). Majority of the students responded appropriately to the principal uses of ECT. Few believed that ECT was an out-moded form of treatment, that the procedure was cruel and barbaric, that psychiatrists who still administered ECT were wicked and not responsible physicians, and that it caused permanent brain damage. The total mean score of the students was $7.53 \pm 2.65$. Fifty eight $(71.6 \%)$ students observed an ECT procedure and followed up the patients during the posting. They scored $7.17 \pm 2.55$ while $23(28.4 \%)$ students who had not observed the procedure scored $6.98 \pm 1.92$ on the QuAKE $(t=-0.36, p=0.72)$. Thirty one (38.3\%) students who would accept the procedure if indicated scored $7.14 \pm 2.21$ while $50(61.7 \%)$ of them who would not allow ECT carried out on them scored $6.88 \pm 1.96(t=0.56, p=0.58)$. The

"Corresponding author.

How to cite this paper: Igwe, M.N., Ndukuba, A.C., Attama, C.M., Ogbonna, P.N. and Igwe, C. (2014) Electroconvulsive Therapy in the Eyes of Undergraduate Nursing Students. Open Journal of Nursing, 4, 818-823.

http://dx.doi.org/10.4236/ojn.2014.412087 
mean score of $29(35.8 \%)$ students who might pursue psychiatry as a career was $8.10 \pm 1.90$ while $52(64.2 \%)$ of them who would not specialise in psychiatry scored $6.05 \pm 1.79(t=5.00, p<0.001)$. The total mean score on the QuAKE was low among the student nurses. Therefore, there is a need to improve undergraduate nursing education on ECT.

\section{Keywords}

\section{Electroconvulsive Therapy, Undergraduate, Nursing Students}

\section{Background}

Ugo Cerletti, an Italian Professor of neuropsychiatry and his colleague Lucio Bini introduced electroconvulsive therapy (ECT) in 1938 as a biological treatment in psychiatry [1] Since then ECT has been established to be particularly effective in major depression (single episode or recurrent), bipolar disorder (depressed, mania or mixed), acute schizophrenia (especially when catatonic, positive or affective symptomatology is prominent) and schizoaffective disorder [2]-[5]. Despite the fact that ECT is a safe and effective procedure, its use has continued to attract controversy with considerable stigma associated with it. This often overshadows the established effectiveness. The use of ECT is also associated with myths and misconceptions among lay people, medical professionals and the media [6] [7]. These tend to worsen the stigmatization. Thus, it is often underutilized and disregarded as a form of treatment [8].

Probably, one possible way to overcome this is for health professionals to be adequately educated and informed about ECT practice. Patients need to make informed decisions before consenting to ECT and this process can be influenced by preconceived ideas and evidence based scientific facts [9].

Registered nurses have been observed to have more knowledge and more positive attitudes than student nurses towards ECT. The more number of years that the registered nurses have spent in mental health and the greater number of patients undergoing ECT they have observed correlated positively with higher levels of knowledge about ECT. Also the number of patients they have had contact with and their level of knowledge about ECT correlated significantly with more positive attitudes towards the procedure [10].

Higher level of knowledge about ECT has also been reported to be associated with the length of experience of the nurses and attitudes significantly related to the degree of contact between the nurses and patients receiving the therapy. Hence, nurses who obtain higher knowledge scores are more likely to show more positive attitudes [11].

A study has shown that nursing students compared with medical students have significantly lower knowledge and more negative attitudes to ECT. Strangely, exposure to the procedure of ECT fails to improve the nursing students' attitudes to the therapy [7].

It had been observed that knowledge and attitude scores were higher among staff mental health nurses compared to student mental health nurses. More years of experience significantly correlated with higher level of knowledge and positive attitudes among staff mental health nurses [12]. Majority of the respondents believed that ECT was beneficial to the patients but was overused and suggested that there should be guidelines for its use in Nigeria.

Nursing students and nursing staff of a tertiary health care facility in eastern Nepal viewed ECT as an effective method of treatment. However, nursing students had more positive views towards ECT than the nursing staff [8].

Significant differences in attitudes to and knowledge of ECT between psychiatrists, psychologists, nurses and social workers have been reported, with psychiatrists being most favourably disposed and most knowledgeable, followed by nurses, social workers and psychologists in that order [13].

Nurses' role in ECT is multifaceted and usually includes providing education and support, performing pretreatment and post treatment nursing assessments and observing the patient responses [14]. Also nurses spend more time with patients and by the nature of their work relate more closely with them. Hence, nurses' knowledge of and attitude to ECT is important because it may be conveyed to patients [10]. Undergraduate nursing students shortly would qualify and become caregivers. It is important that before they qualify, their training would be able to make them have a better understanding of ECT as an efficient and safe form of physical treat- 
ment. Poor knowledge, negative attitude and bias towards ECT by the nurses may translate to poor education and support to patients from whom they are expected to obtain informed consent before an ECT procedure.

This study assessed the perception of undergraduate nursing students of a Nigerian university towards ECT.

\section{Design and Methods}

\subsection{Location of Study}

The study was carried out at the Federal Neuropsychiatric Hospital, Enugu. The hospital started in 1962 as an outpatient unit located at the blood bank of General Hospital Enugu. Shortly after the Biafran-Nigerian Civil War in 1970, the hospital moved to a private facility and then to its current site at New Haven, Enugu. The hospital was taken over by the federal government in 1995 from the state government and it provides mental health services to people of south-eastern, some parts of south-south and north-central geopolitical zones. Undergraduate nursing students from University of Nigeria, Enugu campus have their 8 weeks mental health posting in the hospital. The Bachelor of Science in Nursing takes a period of five years to complete.

\subsection{Ethical Approval}

The ethical approval for the study was obtained from the Institutional Review Board (IRB) of Federal Neuropsychiatric Hospital, New Haven, Enugu, Enugu State, Nigeria. Written informed consent was also obtained from the students that participated in the study.

\subsection{Participants}

The participants involved in this study were all consenting final year undergraduate nursing students of University of Nigeria, Enugu campus. The study was done in May, 2011.

Eighty one undergraduate nursing students consented to participate in the study in a class of 120 students giving a response rate of $67.5 \%$. All the consenting students were administered the socio-demographic questionnaire and the Questionnaire on attitude and knowledge of electroconvulsive therapy. The study was a point survey as students were required to fill the questionnaires immediately. All relevant lectures and practical/ clinical exposures in psychiatry as prescribed in their academic curricula have been done.

\subsection{Materials}

1) Socio-demographic questionnaire

A socio-demographic questionnaire was used to obtain information like gender, age, marital status and duration of posting.

2) Questionnaire on attitude and knowledge of electroconvulsive therapy (QuAKE)

This is a 16-item questionnaire. Responses on the questionnaire are true, false or don't know. A correct answer is scored 1, and a wrong or don't know answer is scored 0 . A minimum score of 0 and a maximum score of 16 are possible. The questionnaire has been shown to have good internal consistency and split-half reliability [13]. Permission to use the QuAKE has been obtained from Professor Martin Orrel on behalf of the authors. Eight additional questions were added to assess the attitudes and wider scope of knowledge of electroconvulsive therapy among the students.

\subsection{Procedure}

The socio-demographic questionnaire and the QuAKE were administered to the students in a classroom setting. The questionnaires were completed and collected immediately from the respondents. This was to avoid consultation of study materials or discussion with colleagues which could have influenced the students' responses to the questions on the QuAKE.

\subsection{Statistical Analysis}

Statistical analysis was carried out using the Statistical Package for Social Sciences (SPSS, Version 16). Frequency counts were done and factors that correlated with knowledge and attitudes determined. Statistical significance was set at $\mathrm{p}=0.05$. 


\section{Results}

A total of 81 students participated in the study. There were sixty one (75.3\%) female and twenty (24.7\%) male students. The total mean age of the students was $23.5 \pm 2.3$ years. Seventy four $(91.3 \%)$ of them were single while $7(8.7 \%)$ were married. Table 1 shows the socio-demographic profile of the students and sources of their opinion and knowledge of ECT.

\subsection{Personal Views and Knowledge of ECT}

Fifty eight (71.6\%) of the students had observed an ECT procedure. Seventy eight (96.3\%) of the students identified major depressive episode, $74(91.4 \%)$ schizophrenia and $68(84 \%)$ mania as the main psychiatric syndromes that respond to ECT. Thirty two (39.5\%) students believed that ECT is an out-moded form of treatment while $12(14.8 \%)$ viewed the procedure as cruel and barbaric. Four students $(4.9 \%)$ held the opinion that psychiatrists who still administer ECT are wicked and not responsible physicians while $16(19.8 \%)$ believed that the procedure is often misused by healthcare providers. Fifty eight $(71.6 \%)$ suggested that the procedure should be guided by legislation in Nigeria. Seventy $(86.4 \%)$ knew the number of courses usually given in a single course of treatment for a patient. Eleven students (13.6\%) indicated that ECT causes brain damage. Forty six (56.8\%) and $38(46.9 \%)$ believed that ECT is contraindicated in children and the elderly respectively. Forty nine (60.5\%) would accept ECT as form of therapy if indicated whereas 39 (48.1\%) may consider pursuing psychiatry as a career in future after graduation.

\subsection{Pattern of Scores on the QuAKE}

The total mean score of the students was $7.53 \pm 2.65$. Fifty eight $(71.6 \%)$ students who observed an ECT procedure and followed up the patients during the posting scored $7.17 \pm 2.55$ while $23(28.4 \%)$ students who had not observed the procedure scored $6.98 \pm 1.92$ on the QuAKE $(\mathrm{t}=-0.36, \mathrm{p}=0.72)$. Thirty one $(38.3 \%)$ students who would accept the procedure if indicated scored $7.14 \pm 2.21$ while $50(61.7 \%)$ of them who would not allow ECT carried out on them scored $6.88 \pm 1.96(\mathrm{t}=0.56, \mathrm{p}=0.58)$. The mean score of $29(35.8 \%)$ students who may pursue psychiatry as a career was $8.10 \pm 1.90$ while $52(64.2 \%)$ of them who would not specialise in psychiatry scored $6.05 \pm 1.79(\mathrm{t}=5.00, \mathrm{p}<0.001)$. This was statistically significant.

\begin{tabular}{ccc}
$\begin{array}{l}\text { Table 1. Socio-demographic variables of the students with sources of opinion } \\
\text { and knowledge of ECT. }\end{array}$ & Percent \\
\hline & & \\
\hline Gender & 20 & 24.7 \\
Male & 61 & 75.3 \\
Female & & \\
Age (years) & $23.5 \pm 2.3$ & \\
Mean \pm SD & & \\
Marital status & 74 & 91.3 \\
Single & 7 & 8.7 \\
Married & & \\
Mources of opinion and knowledge & 52 & 64.2 \\
Personal observation & 10 & 12.3 \\
Mass media & 14 & 17.3 \\
Newspapers and books & 15 & 18.5 \\
Professional publication & 51 & 63 \\
Explanation from a professional & 65 & 80.2 \\
Lecture in school & 4 & 4.9 \\
Others &
\end{tabular}




\section{Discussion}

Of various sources, explanation from a professional (51\%), personal observation of ECT (52\%) and lecture in school (65\%) contributed most to the students' knowledge of and attitudes toward ECT. Mass media contributed only $10 \%$ as source of knowledge. This is in contrast to a study in India that assessed knowledge and attitudes of medical students towards ECT where mass media was the major source of knowledge about the treatment [15].

Majority of the students responded appropriately to the principal uses of ECT. However, few believed that ECT is an out-moded form of treatment, that the procedure is cruel and barbaric, that psychiatrists who still administer ECT are wicked and not responsible physicians, and that it causes permanent brain damage. Many of them would accept ECT as a form of therapy if indicated and approximately, half of the number of students interviewed may consider pursuing psychiatry as a career in future after graduation. This agrees with a study done at Benin, Nigeria [16].

Many of the students suggested that the procedure should however be guided by legislation in Nigeria. This has also been documented in a similar study conducted recently among staff mental health nurses and student nurses [12].

Greater number of the students observed an ECT procedure at least once or more during their mental health posting. The scores of those who had observed the procedure compared to those who had never observed the procedure was not statistically significant $(\mathrm{p}=0.72)$. Thus exposure to an ECT procedure produced no significant change in score on the QuAKE. It had been earlier reported that exposure to the procedure of ECT failed to improve nursing students' attitudes to the therapy (Byrne et al. 2006).

The mean score of the students who may consider pursuing psychiatry as a career in future was higher while those who would not specialise in psychiatry related careers had lower total mean score. This was statistically significant $(\mathrm{p}<0.001)$.

\section{Limitations}

The QuAKE is a self administered questionnaire. It was administered and collected immediately. This was to avoid consulting study materials or discussion with fellow students which may influence the responses of the students to questions contained in the questionnaire. Thus the QuAKE only gives a point assessment of knowledge. There was no provision to ascertain if a respondent had done a diploma programme in nursing and may have previously observed ECT before the present degree programme. Despite these short comings, the findings from this study should serve as a baseline data for comparison in future especially in South-eastern Nigeria where to the authors' knowledge no such work has been carried out.

\section{Conclusion}

The total mean score on the QuAKE was low among the student nurses. There were also various negative views about ECT among them. Therefore, there is a need to improve undergraduate nursing education on ECT.

\section{Acknowledgements}

We thank all the students who willingly consented to participate in this study.

\section{Authors' Contributions}

MNI, CI, ACM and PNO were involved in collection of data while MNI and CI were involved in writing the initial draft of the manuscript. MNI and ACN did the data analysis. All the authors contributed to the conception of the study and were involved in writing the final draft of the manuscript. All the authors read and approved the final draft of the manuscript.

\section{Competing Interests}

The authors declare that they have no competing interests.

\section{References}

[1] Fink, M. (1984) Meduna and the Origins of Convulsive Therapy. American Journal of Psychiatry, 141, $1034-1041$. 
[2] The UK ECT Review Group (2003) Efficacy and Safety of Electroconvulsive Therapy in Depressive Disorders: A Systematic Review and Meta-Analysis. The Lancet, 361, 799-808. http://dx.doi.org/10.1016/S0140-6736(03)12705-5

[3] American Psychiatric Association (1990) The Practice of Electroconvulsive Therapy: Recommendations for Treatment, Training, Privileging. American Psychiatric Association, Washington DC.

[4] Fink, M. (1979) Convulsive Therapy: Theory and Practice. Raven Press Ltd., New York.

[5] Sadock, B.J. and Sadock, V.A. (2007) Kaplan and Sadock's Synopsis of Psychiatry: Behavioral Sciences/Clinical Psychiatry. 10th Edition, Wolters Kluwer/Lippincotts Williams \& Wilkins, Philadelphia.

[6] McDonald, A. and Walter, G. (2001) The Portrayal of ECT in American Movies. The Journal of ECT, 17, $264-274$. http://dx.doi.org/10.1097/00124509-200112000-00006

[7] Byrne, P., Cassidy, B. and Higgins, P. (2006) Knowledge and Attitudes towards Electroconvulsive Therapy among Health Care Professionals and Students. The Journal of ECT, 22, 133-138. http://dx.doi.org/10.1097/00124509-200606000-00011

[8] Shakya, D.R. and Lama, S. (2010) Electroconvulsive Therapy (ECT): In the Eyes of Nurses of a Tertiary Care Hospital. Health Renaissance, 8, 85-89.

[9] Kavanagh, A. and McLoughlin, D.M. (2009) Electroconvulsive Therapy and Nursing Care. British Journal of Nursing, 18, 1370-1377. http://dx.doi.org/10.12968/bjon.2009.18.22.45564

[10] Wood, J.H., Chambers, M. and White, S.J. (2007) Nurses' Knowledge of and Attitude to Electroconvulsive Therapy. The Journal of ECT, 23, 251-254. http://dx.doi.org/10.1097/yct.0b013e31813e0692

[11] Gass, J.P. (1998) The Knowledge and Attitudes of Mental Health Nurses to Electro-Convulsive Therapy. Journal of Advanced Nursing, 27, 83-90. http://dx.doi.org/10.1046/j.1365-2648.1998.00507.x

[12] James, B.O., Lawani, A.O., Omoaregba, J.O. and Isa, E.W. (2010) Electroconvulsive Therapy: A Comparison of Knowledge and Attitudes of Student Nurses and Staff Mental Health Nurses at a Psychiatric Hospital in Nigeria. Journal of Psychiatric and Mental Health Nursing, 17, 141-146. http://dx.doi.org/10.1111/j.1365-2850.2009.01487.x

[13] Lutchman, R.D., Stevens, T., Bashir, A. and Orrell, M. (2001) Mental Health Professionals' Attitudes towards and Knowledge of Electroconvulsive Therapy. Journal of Mental Health, 10, 141-150. http://dx.doi.org/10.1080/09638230124779

[14] Burns, C.M. and Stuart, G.W. (1991) Nursing Care in Electroconvulsive Therapy. Psychiatric Clinics of North America, 14, 971-988.

[15] Andrade, C. and Rao, N.S. (1996) Medical Students' Attitudes toward Electroconvulsive Therapy: An Indian Perspective. Convulsive Therapy, 12, 86-90.

[16] James, B.O., Omoaregba, J.O. and Olotu, O.S. (2009) Nigerian Medical Students' Attitudes to Unmodified Electroconvulsive Therapy. The Journal of ECT, 25, 186-189. http://dx.doi.org/10.1097/YCT.0b013e31818c7701 
Scientific Research Publishing (SCIRP) is one of the largest Open Access journal publishers. It is currently publishing more than 200 open access, online, peer-reviewed journals covering a wide range of academic disciplines. SCIRP serves the worldwide academic communities and contributes to the progress and application of science with its publication.

Other selected journals from SCIRP are listed as below. Submit your manuscript to us via either submit@scirp.org or Online Submission Portal.
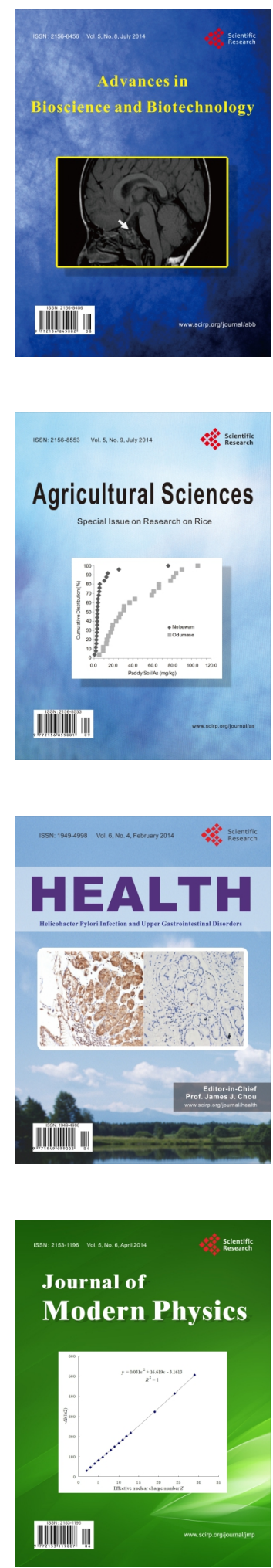
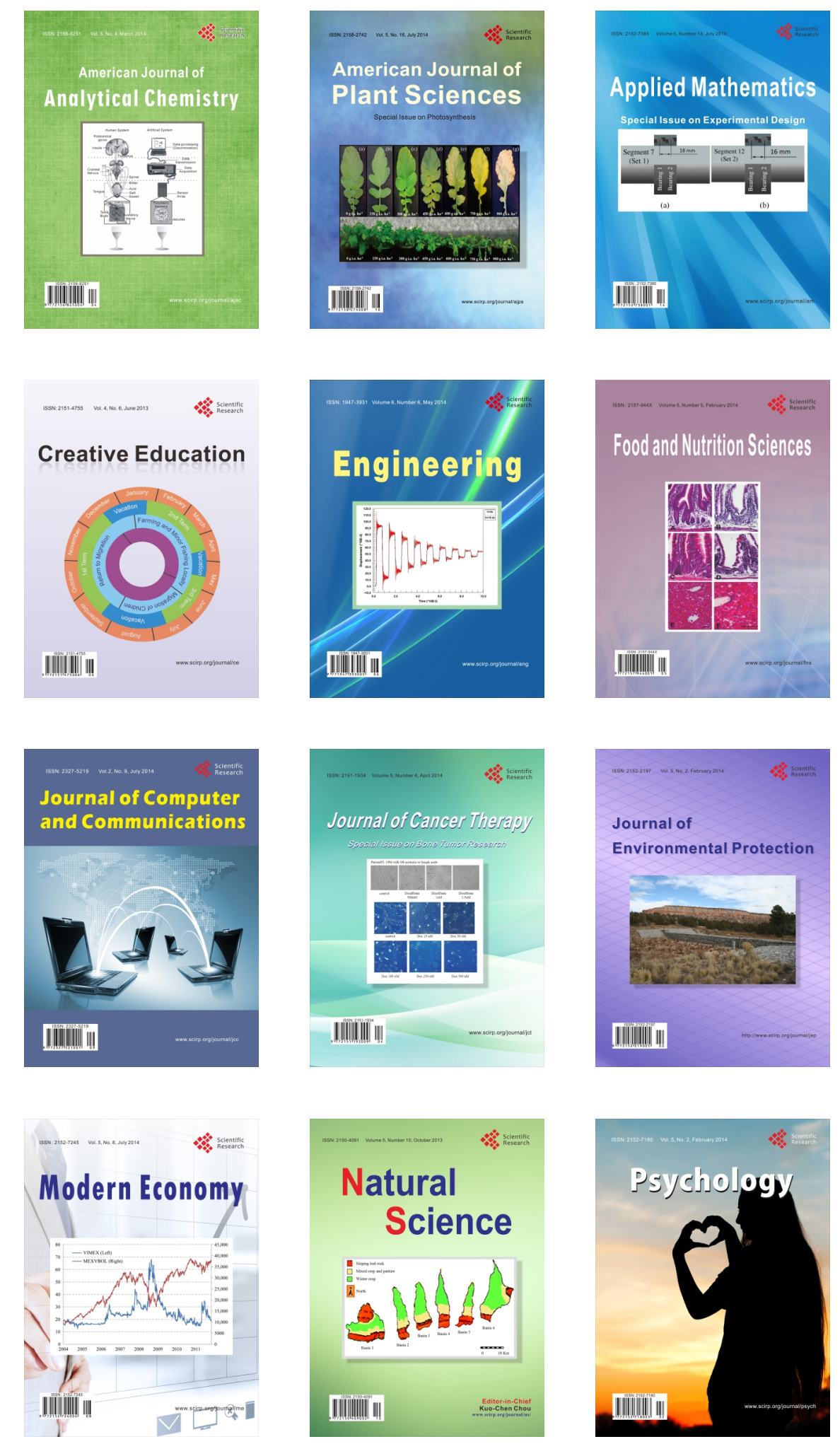